\title{
Perancangan User Interface Aplikasi Mobile Sebagai Media Promosi Digital UMKM Tour dan Travel
}

\author{
Atnis Kurnia Rianingtyas dan Kartika Kusuma Wardani \\ Departemen Desain Produk, Fakultas Arsitektur Desain dan Perencanaan, \\ Institut Teknologi Sepuluh Nopember (ITS) \\ e-mail: kartikawardani.its@gmail.com; atniskr@gmail.com
}

\begin{abstract}
Abstrak-Potensi besar sektor pariwisata di Indonesia mengakibatkan ketatnya persaingan usaha di bidang tour dan travel. Hal ini menyulitkan bagi pemilik usaha skala UMKM karena sebagian besar pangsa pasar dikuasai oleh tour dan travel skala besar. Di sisi lain potensi pasar yang ada memungkinkan media berbasis digital agar dapat bersaing dalam kondisi tersebut. Pemilik usaha tour dan travel skala UMKM membutuhkan desain media yang tepat untuk memperkenalkan kualitas jasa yang dimiliki kepada wisatawan sebagai penggunanya. Metode deep interview dan customer journey map dilakukan untuk memetakan kebutuhan pengguna. Selain itu juga dilakukan studi literatur tentang media user interface, promosi digital dan e-commerce, aplikasi mobile eksisting, dan karakteristik wisatawan yang didapat dari penelitian sebelumnya, buku, jurnal, dan artikel. Keseluruhan proses perancangan menggunakan metode desain kontekstual kemudian hasilnya dirangkum, diolah secara keseluruhan dan disintesis menjadi sebuah konsep desain interface aplikasi mobile sebagai dasar dari perancangan ini. Aplikasi mobile ini menggunakan sistem operasi android. Desain yang dihasilkan meliputi pemetaan kebutuhan pengguna, dan desain user interface yang dirancang berdasarkan riset. Selain itu, UMKM tour dan travel juga mendapatkan perencanaan strategi promosi yang terintegrasi dengan konten di dalam aplikasi. Konsep user interface aplikasi mobile dapat diterapkan dan dikembangkan ke berbagai daerah. Adanya desain user interface aplikasi mobile ini diharapkan dapat menyampaikan informasi kualitas jasa yang dimiliki oleh UMKM tour dan travel dapat kepada wisatawan sebagai pengguna dari aplikasi mobile.
\end{abstract}

Kata Kunci-user interface, aplikasi mobile, marketplace, tour and travel, UMKM.

\section{PENDAHULUAN}

$\mathrm{P}$ ARIWISATA salah satu sektor industri yang berpotensi besar di Indonesia. Hal ini dibuktikan dengan jumlah wisatawan mancanegara ke Indonesia pada tahun 2017 mencapai 14 juta lebih [1], sedangkan wisatawan domestik pada bulan Januari-Oktober 2017 sudah mencapai lebih dari 252 juta wisatawan [2]. Jumlah ini diprekdisikan akan terus meningkat seiring perubahan perilaku masyarakat saat ini yang menjadikan berwisata sebagai bagian dari gaya hidup. Hal ini kemudian juga menyebabkan permintaan dan kebutuhan yang beragam dari masyarakat, terutama yang berkaitan dengan sektor pariwisata.
Meningkatnya antusiasme masyarakat juga menjadi alasan munculnya banyak biro tour dan travel baru. Disamping itu ternyata $70 \%$ dari pasar yang ada sudah dikuasai oleh pemilik usaha skala besar [3]. Hal ini membuat persaingan yang ada semakin ketat bagi pemilik usaha tour dan travel skala UMKM sehingga masing-masing biro tour dan travel saling berlomba mendapatkan konsumen menggunakan berbagai jenis media promosi.

Pasar Indonesia memiliki potensi yang bagus untuk kegiatan promosi digital. Hal ini didukung oleh data dari Kominfo tahun 2017 yang menyatakan bahwa jumlah pengguna internet di Indonesia menduduki peringkat 6 di dunia dan 70\% adalah pengguna ponsel yang sebagian besar dapat dengan mudah terhubung ke internet [4]. Ini adalah peluang bagi aplikasi mobile sebagai pilihan media promosi digital yang tepat untuk memperkenalkan kualitas UMKM tour dan travel kepada masyarakat.

Perancangan aplikasi mobile sendiri meliputi beberapa hal seperti perancangan sistem teknis dan manajemen aplikasi, user experience, user interface, hingga pengembangan promosi. Dari beberapa hal tersebut, user interface adalah salah satu yang aspek yang penting karena berhubungan langsung dengan wisatawan sebagai pengguna. Kemudahan dan keberhasilan pengguna menggunakan aplikasi dan menjalankan tugasnya di dalam aplikasi dengan baik akan berdampak pada kepuasan pengguna hingga brand positioning aplikasi di tengah media yang sejenis. Fungsinya sebagai media yang menyampaikan informasi aplikasi dan pengalaman pengguna adalah faktor penentu keberhasilan sebuah aplikasi mobile yang harus dirancang dengan baik.

\section{URAIAN PENELITIAN}

\section{A. User Interface}

ISO menetapkan standar definisi untuk user interface (UI) yaitu semua komponen sistem interaktif (software amaupun hardware) yang meyediakan informasi dan kontrol kepada pengguna untuk menyelesaikan tugas tertentu dengan sistem interaktif. Beberapa elemen yang termasuk dalam UI adalah window, icon, menu, pointer.

Selain aspek estetika yang tampak secara visual, desain user interface harus dapat menyampaikan fungsinya. Menurut studi Nielsen, usability adalah tujuan akhir dari desain user 
interface. Komponen yang menentukan usability sebuah desain adalah kemudahan untuk dipelajari, efisiensi, ingatan pengguna terkait fungsi aplikasi setelah beberapa kali menggunakan, kesalahan yang dilakukan pengguna, dan kepuasan pengguna.

\section{B. Aplikasi Mobile}

Untuk menentukan jenis aplikasi yang akan dibuat diperlukan informasi mengenai jenis aplikasi mobile yaitu aplikasi native, aplikasi web, dan aplikasi hybrid. Dari analisis tentang kelebihan, kekurangan, dan kesesuaian dengan konsep perancangan sehingga aplikasi native adalah yang akan dikembangkan. Salah satu kelebihannya adalah optimalisasi pengalaman yang akan didapatkan oleh pengguna melalui grafis, gambar, skrip dan data aplikasi.[5]

\section{Digital Marketplace}

Sebagai pengembangan dari e-commerce, beberapa komponen utama digital marketplace adalah memfasilitasi transaksi antara penjual dan pembeli secara online, membantu mempromosikan barang dari penjual dan menyediakan tempat berjualan, dan pembeli dapat melakukan pembelian langsung saat itu juga dengan menekan tombol "beli" kemudian mentransfer sejumlah uang. Marketplace menjadi sebuah media yang memfasilitasi banyak pedagang untuk berjualan.

\section{Promosi Digital}

Promosi digital adalah bentuk kegiatan promosi dengan menggunakan media interaktif dan media internet untuk menghubungkan penjual dengan pembeli yang sudah teridentifikasi [6]. Kelebihannya adalah profil pembeli yang sudah spesifik sehingga dapat mengoptimalkan konten dan desain sesuai dengan karakter pembeli.

\section{E. UMKM Tour dan Travel}

Menurut Undang-undang Nomor 20 Pasal 1 Tahun 2008, UMKM yang dimaksud dengan usaha mikro, usaha kecil dan usaha menengah adalah usaha ekonomi produktif yang berdiri sendiri, yang dilakukan oleh orang perorangan atau badan usaha yang bukan merupakan anak perusahaan atau bukan cabang perusahaan yang dimiliki, dikuasai, atau menjadi bagian baik langsung maupun tidak langsung dari Usaha Menengah atau Usaha Besar yang memenuhi kriteria sesuai dengan jenis usahanya (usaha mikro, usaha kecil, atau usaha menengah).

\section{METODOLOGI PERANCANGAN}

\section{A. Alur Penelitian}

Penelitian keseluruhan untuk merancang aplikasi mobile menggunakan metode desain kontekstual yang terdiri dari dua tahap yaitu tahap kebutuhan dan solusi, dan tahap validasi konsep. Tahap kebutuhan dan solusi bertujuan untuk mengumpulkan data kemudian merancang konsep aplikasi. Alur penelitian dapat dilihat lebih lengkap pada gambar 1.

Pada tahapan desain kontekstual, perancangan UI masuk ke dalam tahapan validasi konsep yang ekseukusi dengan mempertimbangkan hasil riset pada tahap kebutuhan dan solusi.
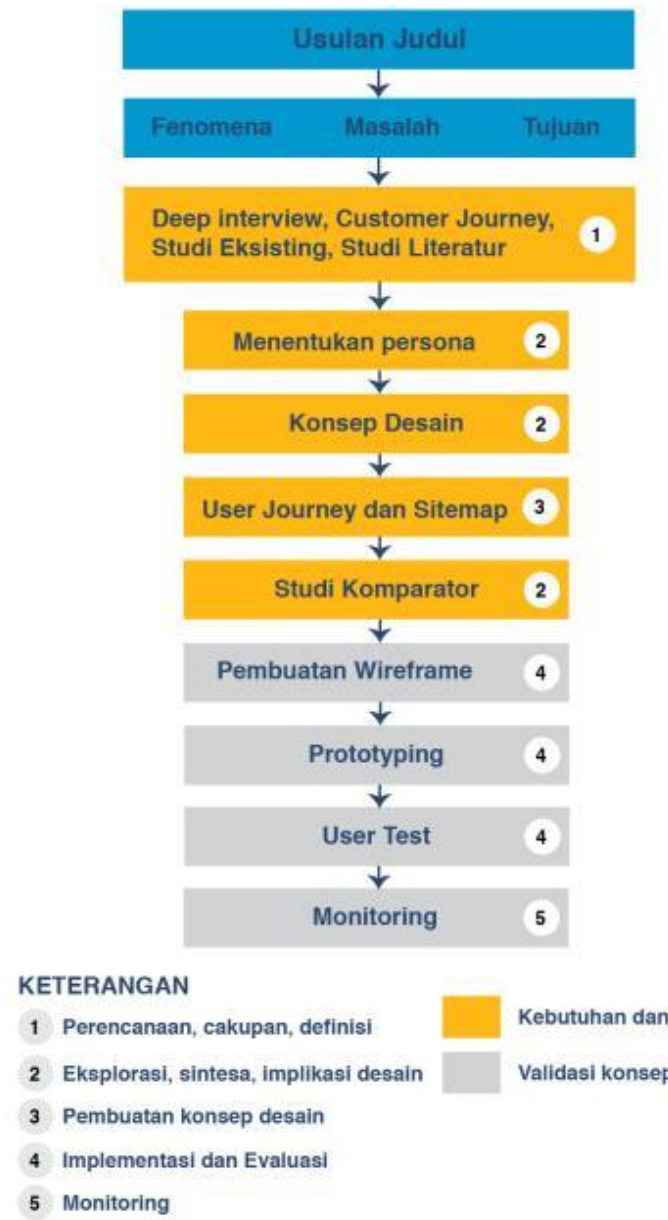

Kebutuhan dan solusi Validasi konsep

Monitoring

Gambar 1. Alur perancangan.

\section{B. Deep Interview}

Hal pertama yang dilakukan untuk memetakan kebutuhan pengguna adalah deep interview. Metode deep interview bertujuan untuk mengumpulkan data tentang karakter, kebiasaan, dan kebutuhan pengguna. Hal ini nantinya menentukan gaya desain user interface yang akan dirancang.

Beberapa narasumber dipilih sebagai sample user dengan tiga kriteria yaitu: belum menikah dan belum bekerja, belum menikah dan sudah bekerja, sudah menikah dan sudah bekerja.

\section{Costumer Journey Map}

Data kebutuhan pengguna didapatkan dengan mempelajari costumer journey dari produk eksisting. Hasil dari penelitian ini kemudian dicari insight dan dilakukan evaluasi peluang. Pada penelitian ini eksisting yang digunakan adalah aplikasi mobile Ezy Travel. Sample user yang diambil datanya memiliki kriteria yang sama dengan narasumber deep interview.

\section{Studi Literatur}

Studi literatur bertujuan untuk menambah wawasan penulis tentang dasar perancangan, teori-teori, dan perkembangan yang berguna untuk proses pembuatan desain dan iterasi prototip. Studi ini dapat dilihat pada bab sebelumnya tentang studi acuan. 


\section{E. Studi Eksisting}

Studi eksisting bertujuan untuk mempelajari produk serupa atau yang terkait untuk kemudian dievaluasi dan dijadikan bahan pertimbangan dalam melalukan. Beberapa eksisting yang dipelajari adalah yang berhubungan dengan marketplace atau pariwisata yaitu Traveloka, Trip Advisor, Kkday, dan Tokopedia.

\section{F. User Persona}

Persona sangat bermanfaat untuk efektifitas penelitian terhadap pelanggan dengan membuat profil fiksi pengguna. Data untuk membuat persona pengguna didapatkan dari rangkuman metode sebelumnya dari mulai studi literatur, deep interview hingga customer journey map. Detail persona aplikasi mobile dapat dilihat pada gambar 2 .

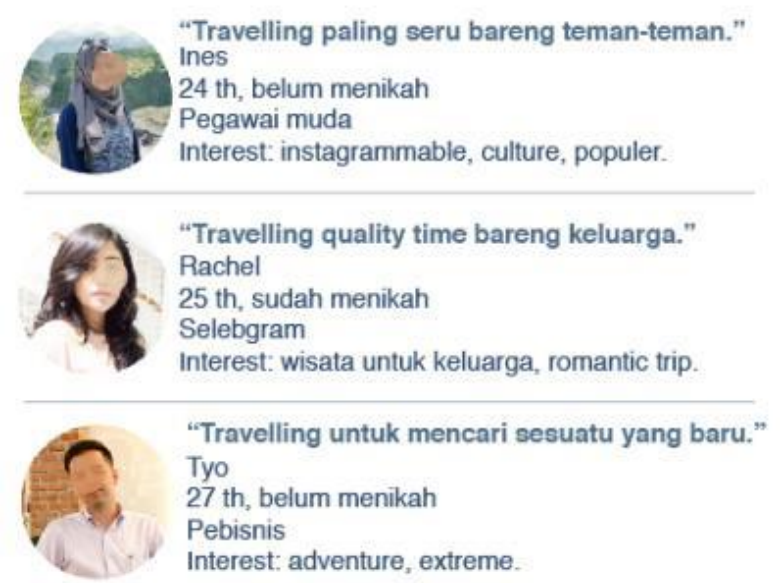

Gambar 2. User Persona.

\section{G. Prototyping}

Setelah penelitian yang menghasilkan rancangan pengguna experience dan ditentukan persona dari aplikasi mobile, tahapan selanjutnya adalah pembuatan prototype aplikasi. Proses pembuatan dilakukan langsung pada software digital seperti pada gambar 3 .

Proses pembuatan prototipe dimulai dengan pembuatan alternatif 1 (gambar 11) yang kemudian dievaluasi dengan user test. Setelah proses perbaikan desain maka dihasilkan alternatif 2 dan alternatif 3 (gambar 11). Dari kedua alternatif tersebut, kemudian didapatkan desain akhir user interface aplikasi.

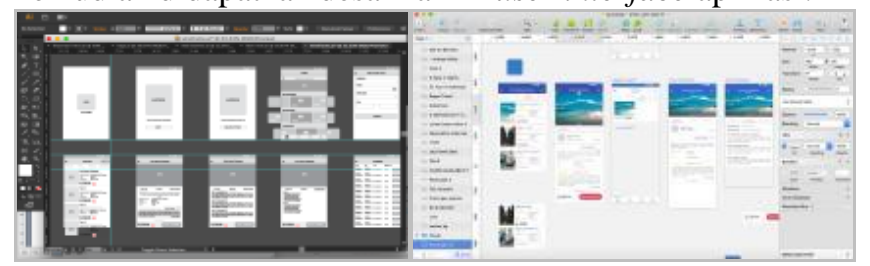

Gambar 3. Proses prototyping pembuatan wireframe aplikasi.

\section{H. Riset Eksperimental}

Riset eksperimental atau Usability Testing dilakukan pada tahap User Testing. Metode ini bertujuan untuk mendapatkan masukan dan kritik dari sample user maupun ahli. User test dilakukan dua kali, yang pertama pengujian prototip desain user interface sebelum dilanjutkan ke tahap pengembangan selanjutnya adalah pengujian desain aplikasi yang sudah berfungsi.

\section{KONSEP DESAIN}

\section{A. Target Pengguna}

Target utama dari perancangan ini adalah dewasa muda yang sudah mempunyai penghasilan berusia 24-35 tahun, menyukai kegiatan travelling, dan ingin berlibur dengan mudah dan nyaman. Target sekundernya adalah tahap usia peralihan antara remaja dan dewasa yaitu 18-23 tahun dengan asumsi mereka juga menyukai kegiatan travelling namun kemampuan finansial lebih terbatas.

\section{B. Keywords}

Setelah mensintesis seluruh proses penelitian mulai dari fenomena, rumusan masalah, batasan masalah, hasil penelitian (deep interview, customer journey map), mendefinisikan karakter pengguna, maka dirumuskan kata kunci dari rancangan aplikasi yaitu travel, modern dan informative.

Dari keywords tersebut, nama aplikasi mobile adalah "Touraway" berasal dari gabungan kata tour dan getaway. Perancangan desain user interface akan berpedoman pada kata kunci dan nama aplikasi dalam mengolah visual.

\section{Arsitektur Informasi}

Arsitektur informasi berfungsi sebagai pedoman alur kerja aplikasi mobile Touraway. Fungsinya juga untuk membatasi jumlah halaman yang harus dibuat dan membatasi perancangan sesuai dengan tujuan.

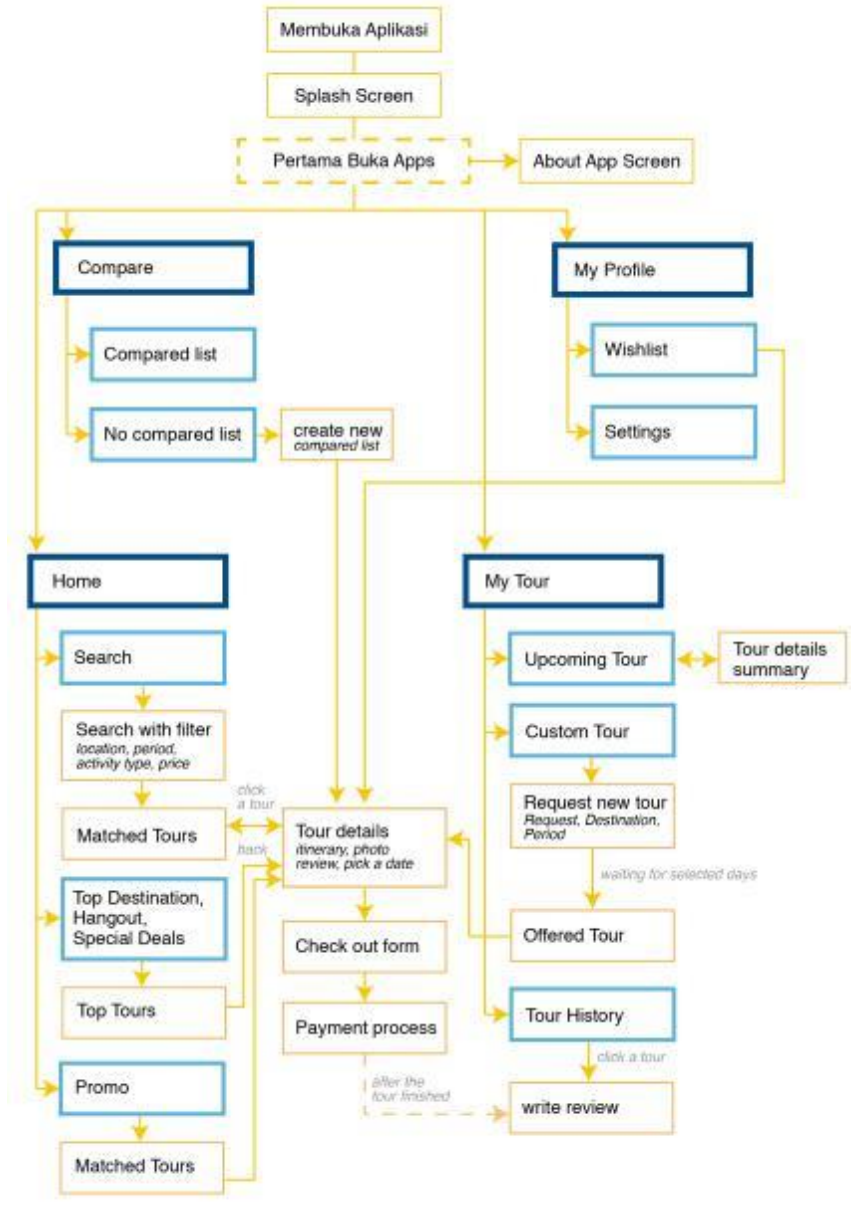

Gambar 4. Arsitektur Informasi Aplikasi Touraway. 


\section{Teknis Aplikasi Mobile}

Aplikasi menggunakan platform Android dengan spesifikasi minimal OS 7. Skema warna RGB resolusi 72dpi. Ukuran layar 1080 px X 1920 px.

\section{E. Wireframe}

Konsep aplikasi ditampilkan dalam bentuk bagan visual wireframe sebagai pedoman dalam mendesain interface aplikasi. Rancangan wireframe dan jalan cerita dari aplikasi Touraway yang didapatkan dari penelitian user experience. Wireframe ini kemudian diolah warna dan visualnya menjadi desain user inface aplikasi mobile.

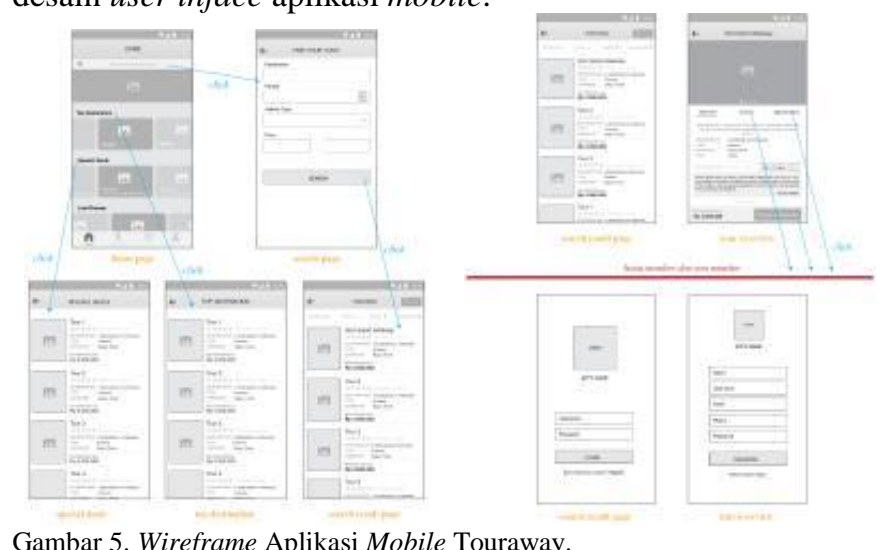

Gambar 5. Wireframe Aplikasi Mobile Touraway.

\section{F. Warna}

Warna oranye kekuningan dipilih sebagai warna utama aplikasi Touraway dengan pertimbangan perbedaan ciri khas visual dari aplikasi eksisting yang didominasi warna biru sehingga aplikasi Touraway dapat lebih diingat dengan perbedaan yang dimiliki.. Warna oranye identik dengan kesan ceria dan bahagia yang diharapkan mewakili perasaan pengguna aplikasi ketika sedang berlibur. Kombinasi warna menggunakan kombinasi komplementer, maka warna biru dipilih sebagai warna sekunder. Fungsi warna biru adalah untuk mempertegas pembagian fungsi perintah. Selain itu warna biru menambahkan kesan terpercaya.

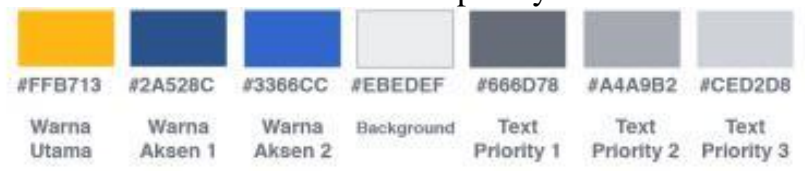

Gambar 6. Skema Warna Aplikasi Mobile Touraway.

\section{G. Typeface}

Pemilihan font Open Sans didasarkan aspek keterbacaan yang baik oleh font hingga ukuran yang terkecil. Selain itu jenis font san-serif dipilih untuk merepresentasikan keyword modern dengan tampilan font yang tidak dekoratif dan memberikan kesan sederhana.

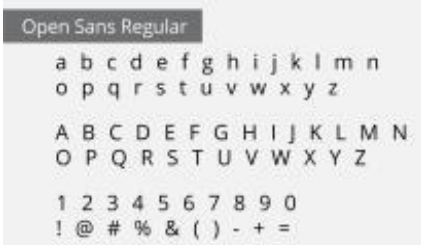

\section{Open Sans Bold}

a b c d e f g h i jk I m n

o p q $\mathrm{s}$ t u v w y z

A B C DEF G H I J K L M N

O P Q R S T U V W X Y Z

1234567890

! @ \# \% \& ( ) - + =

Gambar 7. Typeface Aplikasi Mobile.

\section{H. Foto}

Pengaturan tone warna pada seluruh foto diolah agar tampak alami sehingga pengguna merasa foto tersebut seperti keadaan apa adanya dan tanpa dibuat-buat keindahannya. Saturasi foto sedikit diturunkan, kontras sedikit diturunkan untuk membentuk sebuah foto yang terkesan lebih cinematic. Hal ini disesuaikan dengan hasil wawancara sample user yang menginginkan informasi yang jujur dan nyata.

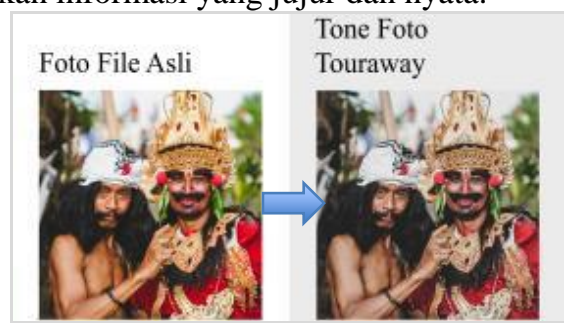

Gambar 8. Filter Foto Aplikasi Mobile Touraway.

\section{Logo}

Konsep logo aplikasi yang sudah didesain sebelumnya menjadi pedoman untuk mengembangkan desain UI pada perancangan ini.

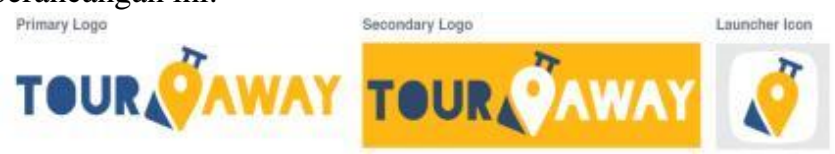

Gambar 10. Logo Aplikasi Mobile Touraway.

\section{J. Ikon}

Ikon sistem secara spesifik adalah bentuk yang mewakili fungsi, perintah dan informasi tertentu pada sistem UI dari sebuah aplikasi. Desain ikon sistem pada aplikasi ini mengacu pada Google Material Design Principle, perpaduan studi eksisting, dan konsep aplikasi. Karakteristik yang ditampilkan dalam desain ikon ini adalah bentuk lengkungan yang diambil dari lengkungan logo aplikasi sehingga membentuk keselarasan desain.

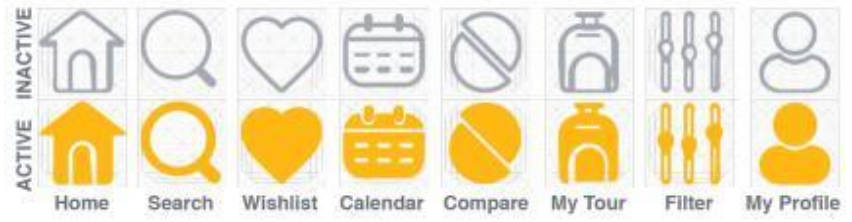

Gambar 11. Ikon Aplikasi Mobile Touraway.

\section{K. Elemen Grafis Pendukung}

Grafis pendukung pada desain UI adalah banner, ilustrasi, dan card (gambar 12). Desain banner terletak pada halaman home paling atas. Konten dari banner adalah promosi dan penawaran khusus dari pihak aplikasi. Konsep desainnya adalah dengan menonjolkan foto sebagai obyek utama, bentuk lengkungan sebagai grafis pendukung, dengan warna oranye sebagai latar belakang. Jika ada tulisan di dalam desain, keterbacaan menjadi pertimbangan utama.

Desain ilustrasi tambahan diletakkan pada beberapa halaman yang belum digunakan fungsinya. Konsep dari ilustrasi adalah obyek utama dengan warna dominan oranye sesuai warna utama aplikasi dengan aksen biru. Desain latar belakang obyek utama menggunakan kombinasi warna abu- 
abu. Gambar latar belakangnya adalah perwakilan destinasi wisata secara umum seperti gunung, pantai, pohon, dan obyek lain yang berhubungan.

Desain card mengambil elemen lengkung pada logo aplikasi sebagai ciri khas visualnya. Tulisan yang ada harus mempertimbangkan aspek keterbacaan terutama karena ukuran card yang kecil.

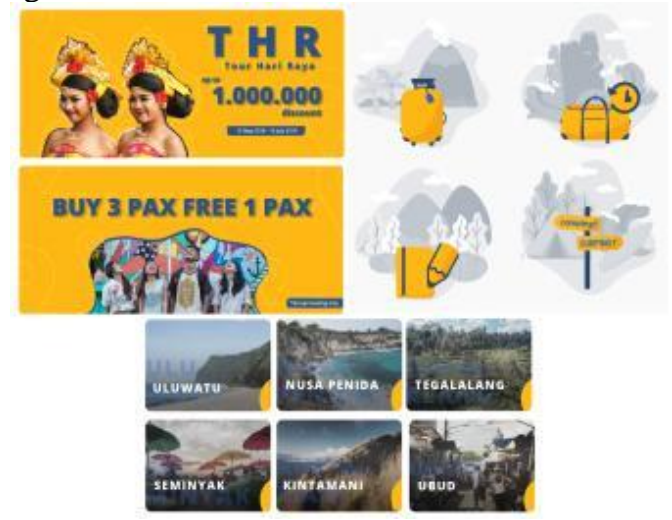

Gambar 12. Elemen Grafis Pendukung Aplikasi Mobile Touraway.

\section{Desain User Interface}

Konsep desain UI didapatkan setelah pengembangan alternatif desain dengan pertimbangan dari user test. Proses pengembangan desain dijelaskan pada metode prototyping.

Pada alternatif 1 dan alternatif 2, desain UI menggunakan warna biru sebagai warna utamanya. Kemudian setelah melalui tahap evaluasi, dirancang alternatif 3 dengan warna dominan oranye dengan pertimbangan identitas visual yang lebih berkarakter dan menonjol dari aplikasi eksisting.

Pada desain alternatif 3 dilakukan beberapa perubahan minor untuk mengoptimalkan fungsi aplikasi kemudian menjadi desain akhir UI aplikasi mobile Touraway yang dibahas pada bab V.

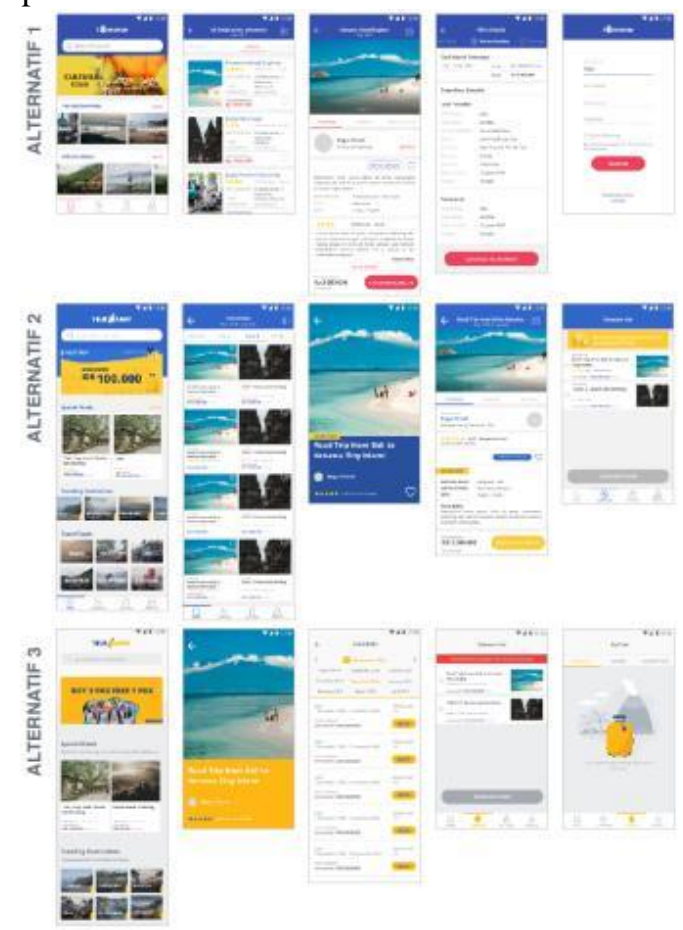

Gambar 13. Alternatif desain UI Aplikasi Mobile Touraway.

\section{PEMBAHASAN DESAIN}

Setelah dilakukan user test dan beberapa perbaikan desain, berikut ini adalah hasil akhir interface aplikasi mobile Touraway sesuai dengan kata kunci travel, modern, dan informatif sebagai acuan hasil akhir desain UI ini.

\section{A. Tampilan halaman dengan ilustrasi}

Beberapa halaman dilengkapi dengan ilustrasi sebagai pelengkap informasi (gambar 14).

\section{B. Tampilan Homepage}

Desain homepage aplikasi mobile Touraway terdiri dari tujuh segmen yaitu pencarian, banner, special deals, trending destination, hangout, travel type, dan review (gambar 15).

\section{Tampilan halaman dengan form}

Beberapa halaman memiliki form yang harus diisi seperti halaman registrasi, tulis review, tulis custom trip, dan edit profile (gambar 16).

\section{Tampilan halaman informasi}

Desain halaman lainnya menampilkan informasi yang berbeda-beda seperti paket wisata, pemesanan, dan lain-lain (gambar 17).

\section{KESIMPULAN/RINGKASAN}

Adanya desain user interface (UI) aplikasi mobile dapat membantu pengguna dalam melakukan tugas dan fungsi dari aplikasi tersebut. Perancangan desain UI yang baik harus didasari oleh penelitan yang berpusat pada pengguna sehingga desain yang dihasilkan dapat dikatakan berhasil. Pada perancangan ini fungsi UI bukan hanya memudahkan pengguna tetapi juga mendukung tujuan utama pembuatan aplikasi mobile yaitu memperkenalkan kualitas jasa UMKM tour dan travel kepada pengguna. Selain itu, desain UI pada perancangan ini juga berfungsi sebagai identitas visual yang membedakan aplikasi Touraway dengan aplikasi eksisting. Semua elemen desain dirancang sesuai dengan kata kunci konsep desain sebagai pedomannya, dan disesuaikan satu sama lain agar menghasilkan kesatuan desain yang selaras. Adanya penelitian ini adalah pelengkap dari penelitian tentang user experience aplikasi mobile Touraway dan dapat dikembangkan menjadi perancangan aplikasi mobile dengan studi yang lebih mendalam mengenai aspek teknis dan pengembangan lainnya.

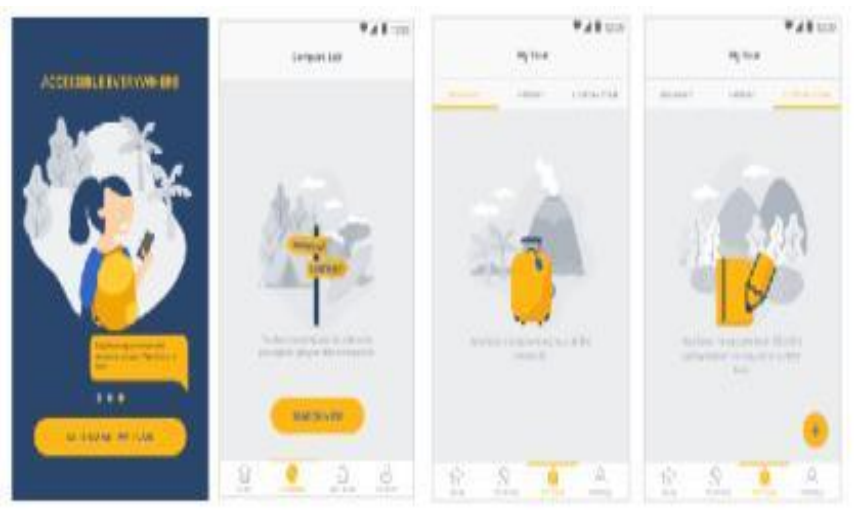

Gambar 14. Halaman Aplikasi Mobile Touraway dengan illustrasi. 


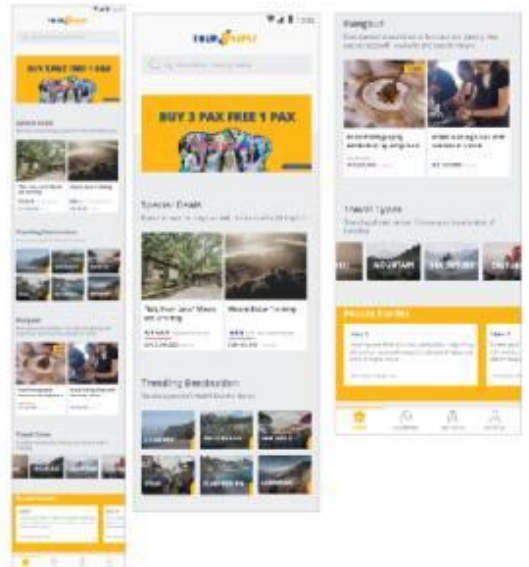

Gambar. 15. Tampilan Homepage Aplikasi Mobile Touraway

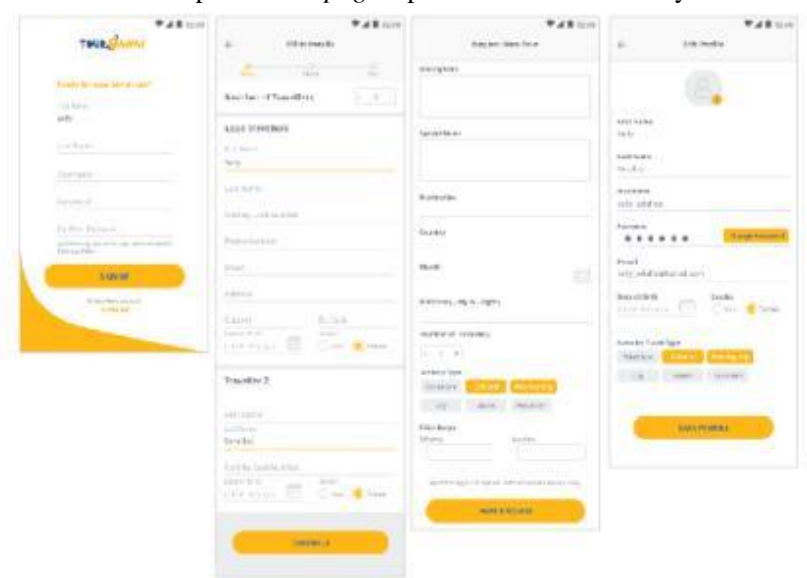

Gambar. 16. Halaman dengan form Aplikasi Mobile Touraway.

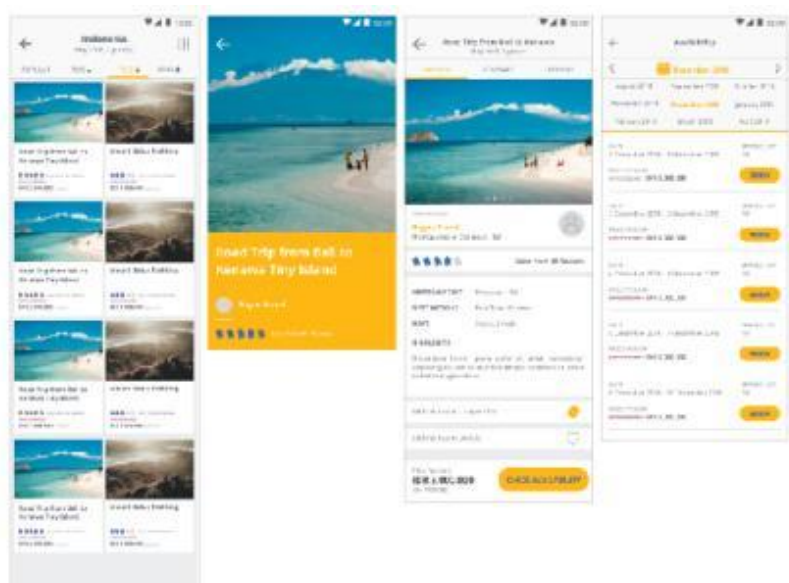

Gambar. 17. Halaman dengan informasi Aplikasi Mobile Touraway

\section{DAFTAR PUSTAKA}

[1] Badan Pusat Statistik Provinsi Bali, "Kunjungan Wisatawan Domestik ke Bali per Bulan, 2004-2017,” Bali, 2017.

[2] Badan Pusat Statistik Provinsi Bali, "Wisatawan mancanegara ke Bali Desember 2017," Bali, 2018.

[3] A. Gunawan, "Analisis Strategi dan Taktik Pemasaran dalam Aktivitas E-commerce untuk Meningkatkan Pertumbuhan PT Golden Rama Express," J. WINNERS, vol. 15, no. 1, pp. 61-71, 2014.

[4] Asosiasi Penyelenggara Jasa Internet Indonesia, "Infografis Hasil Survey Penetrasi dan Perilaku Pengguna Internet Indonesia Tahun 2016," 2016.

[5] International Organization for Standardization, "ISO 9241-210," 2010. [Online]. Available: https://www.iso.org/standard/52075.html. [Accessed: 21-Feb-2019].

[6] N. Coviello, R. Milley, and B. Marcolin, "Understanding IT-enabled interactivity in contemporary marketing," J. Interact. Mark., vol. 15, no. 4, pp. 18-33, Jan. 2001. 